\title{
Real Time Vehicle Monitoring and Tracking System for School Bus via Beagle Bone
}

\author{
Geethanjali.K ${ }^{1}$, Pushparani .M .K ${ }^{2}$ \\ ${ }^{1}$ VTU Belgaum, M. Tech in VLSI Design and Embedded System, MITE, Moodabidri \\ ${ }^{2}$ Sr.Asst. Professor, Dept. of ECE, MITE, Moodabidri
}

\begin{abstract}
Vehicle tracking system is designed for transportation purpose like school transportation and goods transportation. Here Beagle bone based vehicle tracking system for school bus is designed to track the school bus in real time and to provide the safety and security to the students while travelling. The proposed system consists of Beagle bone black, GPS, GSM, Alcohol detector, Door sensor and Eye-blink sensor. The proposed system is placed inside the vehicle in order to track the school bus in real time with date, time, and location. The sensors are used in the proposed system to monitor the driver and vehicle. The sensor gives information during critical situations. In order to monitor properly, the deployment of web server is necessary to display the vehicle data that will store the data and display to clients about the vehicle.
\end{abstract}

Keywords: Beagle bone black, GPS, GSM, door sensor, eye-blink sensor, alcohol sensor

\section{Introduction}

The Beagle bone based vehicle tracking system for school bus is intended to present safety atmosphere to the students. Now a day we are observing a lot of accidents of school buses because of driver's careless whether a driver may be in laziness or drunk driving and also about many children missing. This is because children and their parents don't know the exact routing details. In order to avoid all these problems the beagle bone black is used along with some sensors in this project.

Beagle bone board along with the sensors is placed in the inner part of the vehicle. The map-reading details are updated on the beagle bone board. If the driver drives the vehicle in the wrong path, then message will be sent to the owner and in real time the position of the vehicle can be tracked. Even parents have the opportunity that, they can track the vehicle with Login details provided in the web.

\section{Proposed work}

The proposed method mainly designed for the school bus is

- First, it gives the proper details about the route with date and time.

- Second, about door indication, indicating whether the door is closed or opened.

- Third, whether Driver is in drowsiness or not, if he is in drowsiness it sends message to the owner "driver is sleeping".

- Finally, it will check driver is drunk driving or not, if driver is drunk, then is sends the message that "alcohol detected".

\section{Methodology}

In this project for vehicle monitoring and tracking the option for routing is done by using the Google API, where Google provides efficient routing options. The GPS device is used to show the direction to reach destination from the source. From a security point of view alcohol sensor, door sensor and eyeblink sensor is used. All these sensors are connected to the Beagle bone board and placed in the inner part of the vehicle.

In order to monitor properly, we are deploying web server to display the vehicle data that will store all the data and display to clients about the vehicle and the driver status

\section{Basics introduction about components used}

\subsection{Beagle Bone Board}

Beagle bone black is one of the low priced, communitysupported and more advanced platforms for developers. It boots up the Linux within 10 seconds and get started with a single USB cable. Beagle bone was first launched in 2008, which was larger in size and was more expensive. In 2012, the Beagle bone team has released the latest version of Beagle bone called Beagle bone black with credit card size and less cost. The Beagle bone board is intended by Texas instruments, it's having AM3358 ARM cortex A8 based processor, Giga hertz speed and 2 Giga bits on board memory. There are several embedded Linux boards but beagle bone board is having greater fulfillment and power capability as compared to all other embedded Linux based boards like Arduino Yun, Intel Galileo, and Raspberry pi.

These Linux based boards are more expensive and do not have internal storage as some boards like raspberry pi needs an external SD card. So, beagle bone is better which has better feature like more speed, more memory storage and board cost is also less.

\subsection{GPS}

GPS an acronym stands for global positioning system. First America started the GPS project in 1973 to visibly move the prior guiding along route. At first GPS was engaged in armed force applications. Although the government made the GPS 


\section{International Journal of Science and Research (IJSR) \\ ISSN (Online): 2319-7064 \\ Index Copernicus Value (2013): 6.14 | Impact Factor (2015): 6.391}

system accessible for civilian's use in the year 1980. In 1995 GPS completely came into functional and GPS works in all atmospheric conditions, 24/7 hours/day. GPS gives latitude and longitude information. The GPS makes use of 3 satellites to calculate latitude and longitude and 4 or more satellites to calculate latitude, longitude and altitude.

Whenever the GPS is on, satellites transmit the signal to GPS and GPS receiver receives the signal.GPS helps to know about the time and location of the destination place. It gives the exact location, the directions to reach the destination and the distance between the source and destination.

\subsection{GSM}

GSM stands for global system for mobile communication. It was developed in the year 1970 at Bell laborites. For transmitting mobile voice and data services, GSM operates at different frequency. For exchanging information GSM makes use of Time division multiple accesses [TDMA]. GSM network has some dissimilar cell sizes like macro, micro, umbrella and space cells, and each cell coverage analysis space varies according to the achievement.

\subsection{IR sensor}

In this project IR sensor is used to detect door is closed or opened in school bus. It consists of transmitter, receiver, led and resistor. These IR rays are not visible to the human eye. IR rays are visible by photodiode, which consists of analog and digital sensors. Analog sensor output depends upon the intensity of light received and digital sensor output display in the form of 0 or 1.

In order to detect door is closed or not, digital sensor output is used, i.e., 0 or 1 . If the door is closed, the output will be low ' 0 ' and the output will be high ' 1 ' if door is opened.

\subsection{IR based eye blink sensor}

IR rays are transmitted by IR based eye-blink sensor to the eyes of the driver. If the driver blinks his eye at the normal rate, then the output will be low which means the driver is not in drowsy. If the driver closes his eyes for a particular set time, then the sensor calculates the time and depending upon the calculated time it gives output high indicating the driver is in drowsiness.

\subsection{GAS SENSOR}

The gas sensor consists of the sensing element which detects the gas and the presence of alcohol content then it sends the message to the owner displaying "alcohol detected". And not display any message, when alcohol is not detected.

\section{Working Procedure}

In this project hardware part is divided into two parts.

1. Transmitter

2. Receiver
Transmitter part is shown in fig 1,it consists of Beagle bone black, GPS, GSM, eye blink senor, door sensor ,alcohol sensor.GPS and GSM are connected to $12 \mathrm{v}$ supply, eye blink sensor, door sensor, alcohol sensor are connected to 5v. GPS, GSM and all sensors are connected to Beagle bone board. Alcohol detector is connected to analog to digital converter for monitoring the driver. Door and eye blink sensors are connected to general purpose input output ports to detect whether door is closed properly or not and to detect driver is in drowsiness or not.

Fig 2 shows the receiver part, GUI part will be running separately in personal computer that is our receiver.

This is bidirectional communication between transmitter and receiver by using web servers. Once we choose the destination on GUI the message will be send to transmitter path and that will automatically calculate the waypoints and that will start to fetch the values from the GPS about route and sensors.GUI part will read the data from the web server and that will update in GUI window.

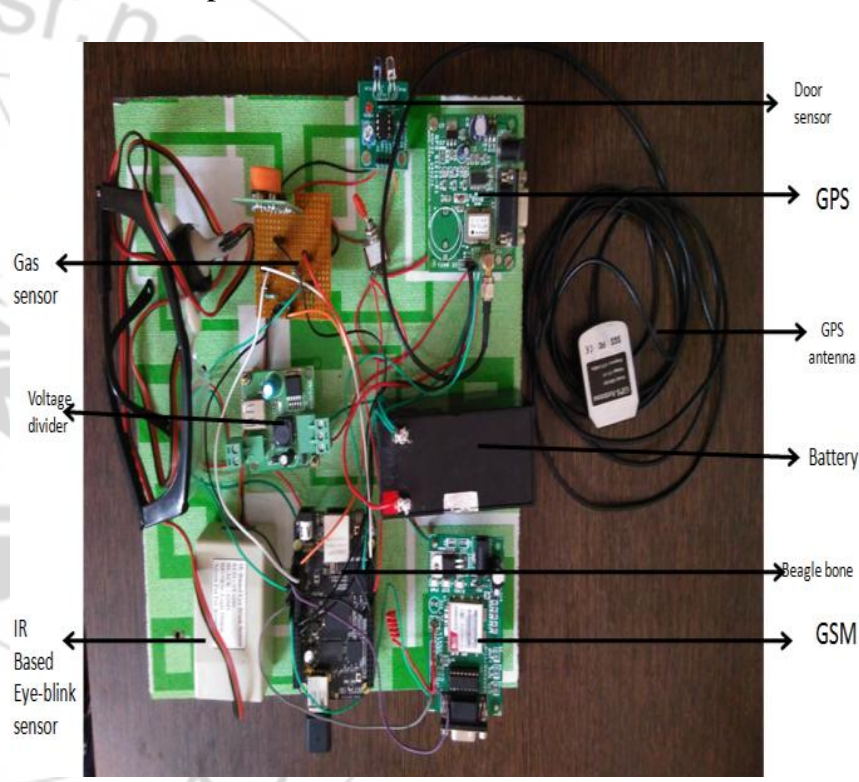

Figure 1: Transmitter part

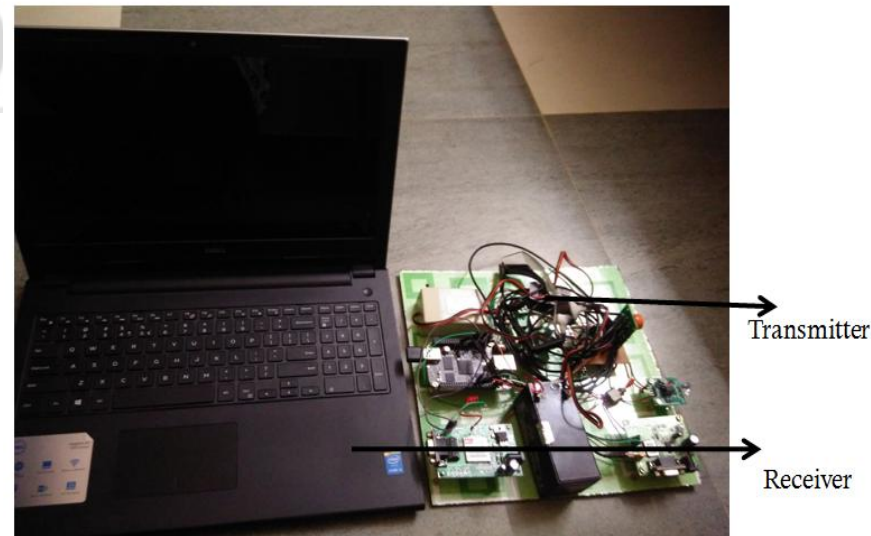

Figure 2: Receiver part

Transmitter part output 


\section{International Journal of Science and Research (IJSR) \\ ISSN (Online): 2319-7064}

Index Copernicus Value (2013): 6.14 | Impact Factor (2015): 6.391

\section{Results}

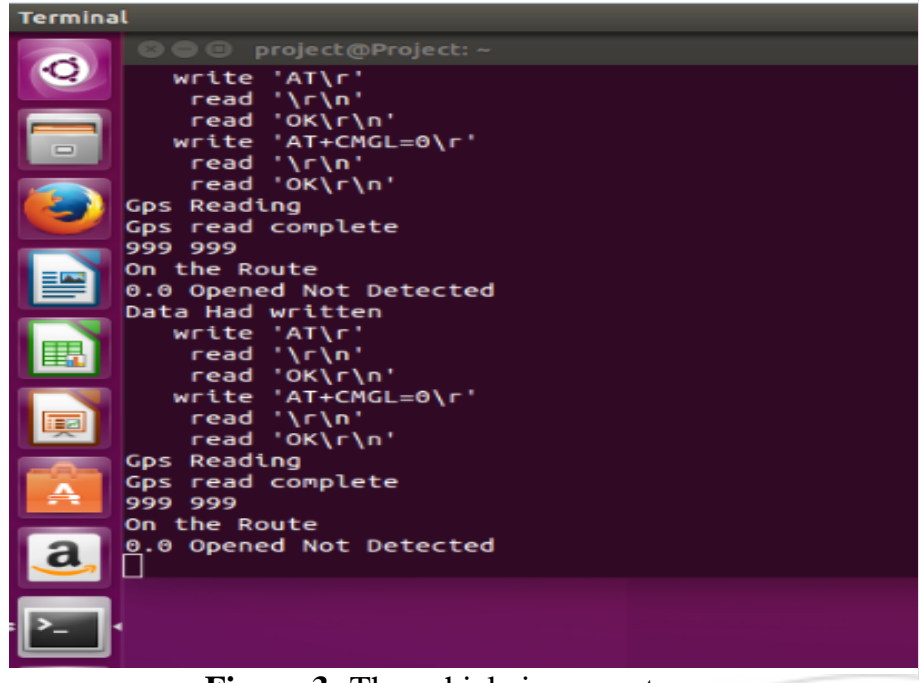

Figure 3: The vehicle is on-route

\section{Receiver part output}

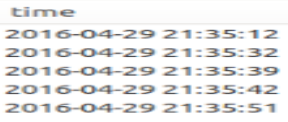

Gpsdata

$13.031626,74.579349$ 13.031026 .74 .579349 $13.031626,74.579349$ $13.031645,74.579350$

Figure 4: lattitude and longitude

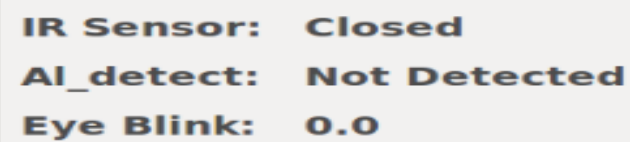

Figure 5: Sensors output

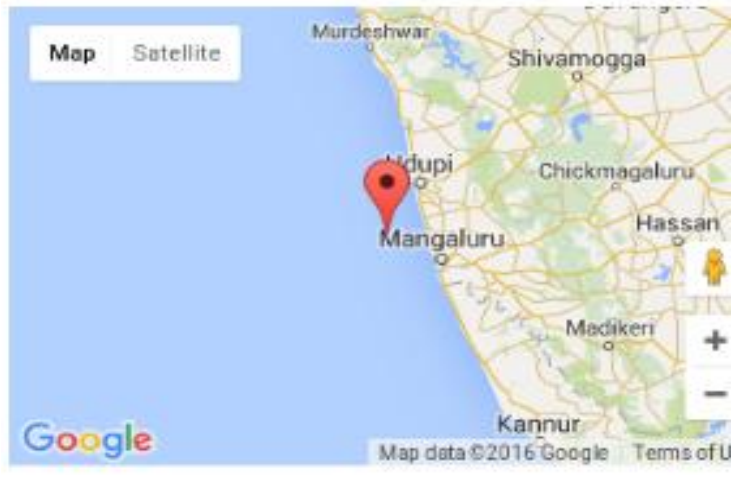

Figure 6: Map
Vehicle Monitoring Using BeagleBone

Gps Log Page

\begin{tabular}{|c|c|c|c|c|c|c|}
\hline No & Date/time & Gps data & Door & Eye close internal & Alcohol level & Route Detection \\
\hline 1 & 2016-04:29 21:34:14 & 13.031626,74.579349 & Closed & 0.0 & Not Detectted & On the Route \\
\hline 2 & 2016-04:29 21:34:23 & 13.031626,74.579349 & Closed & 0.0 & Not Detected & On the Route \\
\hline 3 & 2016-0429 21:34:34 & 13.031626,74.579349 & Closed & 0.0 & Not Detected & On the Route \\
\hline 4 & 2016-04:29 21:34:45 & 13.031626,74.579349 & Closed & 0.0 & Not Detected & On the Route \\
\hline 5 & 201604-29 21:34:48 & 13.031626,74.579349 & Closed & 0.0 & Not Detected & On the Route \\
\hline 6 & 2016-04-29 21:34:51 & 13.031626,74.579349 & Closed & 0.0 & Not Detected & On the Route \\
\hline 7 & 2016-04-29 21:34:53 & 13.031626,74.579349 & Closed & 0.0 & Not Detected & On the Route \\
\hline 8 & 2016-04-29 21:34:57 & 13.031626,74.579349 & Closed & 0.0 & Not Detected & On the Route \\
\hline 9 & 2016-04-29 21:35:02 & 13.031626,74.579349 & Closed & 0.0 & Not Detected & On the Route \\
\hline
\end{tabular}

Figure 7: Webpage output

\section{Conclusion}

Real time vehicle tracking system for school bus with the beagle bone board is proposed in this paper. The proposed system works in real time to track the school bus with position and time. Considering the safety of the students the sensors like door sensor, alcohol sensor and eye-blink sensor are used. If the driver is in drowsy, it sends message to the owner indicating that the "driver is in drowsiness" and it also sends the message to the owner regarding "alcohol detection". By using the IP address, parents can login into the website with user name and login password and can easily track the school bus. Finally, concluded that the proposed system has well featured and everyone can make use of it.

\section{Acknowledgments}

I would like to express my huge gratitude to my guide Ms. Pushparani M.K, Sr. Asst. Professor, Department of Electronics and Communication, MITE, Moodabidri.

\section{References}

[1] Prashant A. Shinde; Y.B.Mane, "Advanced vehicle monitoring and tracking system based on Raspberry pi"IEEE sponsored $9^{\text {th }}$ international conference on intelligent systems and control (ISCO) 2015.

[2] Pengfei zhou; yuanqing zheng;mo li, “ How long to wait? Predicting bus arrival time with mobile phone based participatory sensing,"mobile computing, IEEE transations on,vol.13,no.6,pp.1228,1241,june 2014.

[3] Seokju lee; tewolde,G.; Jaerock kwon, " Design and implementation of vehicle tracking system using GPS/GSM/GPRS technology and Smartphone application, "internet of things(WF-IOT),2014 IEEE world forum on,vol.,no.,pp.353,358,6-8 march 2014.

[4] Hoang dat pham; drieberg,m.; ch cuong Nguyen, "Development of vehicle tracking system using GPS and GSM modem,"open systems(ICOS),2013 IEEE conference on,vol.,no.,pp.89,94,2-4 dec.2013. 
[5] Al rashed, M.A; oumar,O.A.; singh,D., "A real time GSM/GPS based tracking system based on GSM mobile phone," Future generation communication technology (FGCT), 2013 second international conference on,vol., no.,pp.89,94,2-4 nov.2013

[6] Liu; anqi zhang;shaojun li, "vehicle anti-theft tracking system based on internet of things,"vehicular electronics and safety(ICVES),2013 IEEE international conference on,vol.,no.,pp.48,52,28-30 july 2013.

[7] Kumar,R.; Kumar,H., "Availabilty and handling of data received through GPS device: in tracking a vehicle,"advanced computing conference(IACC),2014 IEEE international,vol.,no.,pp.245,249,21-22 feb.2014

[8] Tarapiah, s.; Atalla,S.; "Smart on-board transportation management system geo-casting featured," computer applications and information systems(WCCAIS), 2014 world congress on, vol., no., pp.1,6,17-19 jan.2014.

\section{Author Profile}

Geethanjali .K doing M-tech in final year VLSI design and embedded systems branch, in Mangalore institute of technology and engineering, Moodabidri in the year of 2014-2016. 